\title{
COMPUTER-AIDED INVESTIGATION OF SPECIAL ISSUES OF THE RESPONSE OF SEISMICALLY ISOLATED BUILDINGS
}

\author{
E. MAVRONICOLA, P. POLYCARPOU, L. PAPALOIZOU \& P. KOMODROMOS \\ Department of Civil and Environmental Engineering, University of Cyprus, Cyprus.
}

\begin{abstract}
This paper presents indicative results from the numerical investigation of two special issues of the seismic behaviour of base-isolated buildings, using custom-made software that utilizes modern objectoriented design approaches. The first issue concerns the modelling of the nonlinear behaviour of seismic isolation systems, focusing on the lead rubber bearings (LRBs), which are among the most commonly used seismic isolation systems. In particular, the inaccuracies between the actual behaviour of the LRBs, which can be more precisely represented by the Bouc-Wen model, and the usage of a bilinear inelastic model, which is often used in practice, are assessed through numerical simulations and parametric analyses. The second issue concerns potential pounding of base-isolated buildings with adjacent structures, when the available clearance around a seismically isolated building is limited, during very strong earthquakes. The consequences of potential pounding and the influence of certain parameters on the overall seismic response of base-isolated buildings are also assessed through numerical simulations and parametric analyses using custom-made software.

Keywords: Base/seismic isolation, earthquake, pounding, nonlinear, simulation.
\end{abstract}

\section{INTRODUCTION}

The presented work is founded on research on seismic isolation that had been conducted, 20 years ago, by the last author, under the guidance and supervision of Prof. Jerome J. Connor at the Department of Civil and Environmental Engineering at the Massachusetts Institute of Technology (MIT), during his S.M. Thesis, entitled 'Application of Seismic Isolation as a Performance-Based Earthquake-Resistant Design Method', and later published by the WIT Press [1].

This paper presents two special issues of the seismic response of base-isolated buildings that are investigated independently using custom-made software that utilizes advances in software engineering. In particular, object-oriented programming (OOP), design patterns (DPs), and the Java programming language have been exploited in order to design and implement a flexible and extendable software application that can be effectively used to perform the necessary numerical simulations and parametric studies of base-isolated buildings taking into account these two special issues of interest.

Seismic isolation is used to prevent the disastrous consequences of severe earthquake excitations, by shifting the fundamental eigenperiods of relatively stiff buildings outside the dangerous for resonance range. The superstructure of a base-isolated building is oscillating as an almost rigid body, whereas the interstorey deflections and the absolute floor accelerations can be substantially decreased [1-3]. Large deformations are confined at the seismic isolation level, where seismic isolators, such as the lead rubber bearings (LRBs), can accommodate cycles of large strains. The LRBs in Fig. 1a are elastomeric bearings in which one or more lead plugs are vertically inserted in order to provide a high initial stiffness and an additional hysteretic energy dissipation mechanism. The elastomeric rubber ensures the necessary restoring force to prevent permanent relative displacements at the isolation level, whereas the 
lead plug dissipates energy hysteretically during severe earthquakes, as it is forced by the steel plates to deform inelastically in shear after exceeding its yield stress [1].

The first issue focuses on the modelling of the LRBs, assessing how that modelling may affect the computed peak responses of base-isolated buildings. Experimental results indicate that the shear force-displacement relationship of the LRBs can be well represented by the Bouc-Wen model [4], as shown with a solid line in Fig. 1b. However, a bilinear approximation of the shear force-deformation relationship of the LRBs is often used and adopted by the AASHTO Guide Specifications for Seismic Isolation Design. The bilinear model is characterized by the yielding of the lead core after a critical shear force is exceeded, as shown with a dashed line in Fig. 1b. Prior to the yielding of the lead core, the LRB has an initial stiffness $K_{\text {elastic }}$, which is much higher than the post-yield stiffness $K_{\text {postyield }}$ that corresponds solely to the stiffness of the rubber.

Selected results from parametric studies focusing on the computed peak responses of base-isolated buildings that are modelled using both the bilinear and the Bouc-Wen models, under near-fault ground excitations, are presented, in order to assess the discrepancies between these two models.

The second research project, from which indicative results are presented, investigates the effect of potential pounding of seismically isolated buildings with the surrounding moat walls or adjacent structures (Fig. 2) during very strong earthquake excitations through parametric studies. In practice, there is a possibility of structural pounding of seismically isolated buildings with adjacent structures during very strong earthquakes, mostly due to the large relative displacements at the isolation level, when the width of the clearance that is provided around a seismically isolated building is limited by practical constraints. Although earthquakeinduced pounding incidences between fixed-supported buildings motivated relevant research, very limited research work has been carried out for structural pounding of seismically isolated buildings [5-8], which exhibit quite different dynamic characteristics from conventionally fixed-supported buildings. Selected results are presented from assessing the
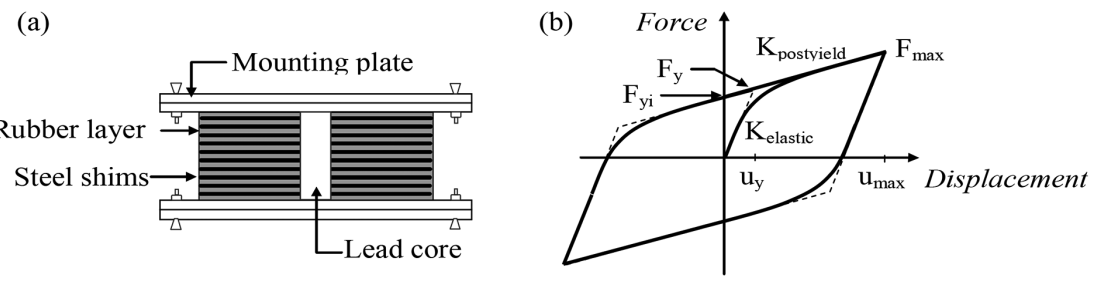

Figure 1: (a) Cross-section, and (b) force-displacement behaviour of an LRB.
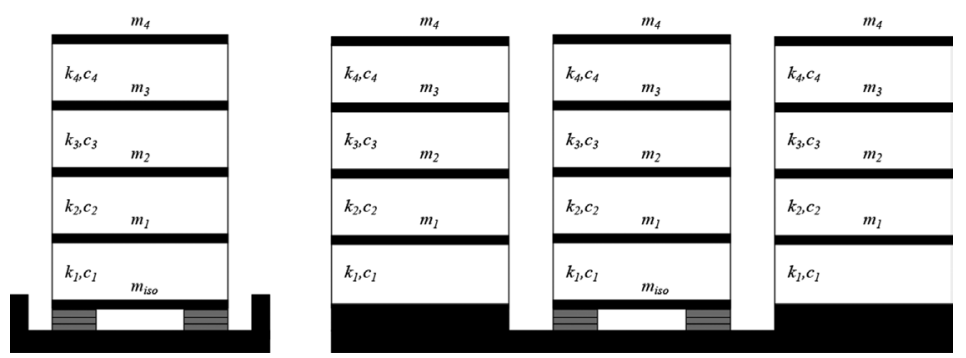

Figure 2: Configuration of a seismically isolated building and adjacent structures. 
influence of structural pounding of a base-isolated building with the surrounding moat wall or adjacent structures on the effectiveness of seismic isolation.

Both research projects require the implementation of structural analysis software that can effectively and efficiently perform large numbers of parametric analyses of base-isolated buildings, with the ability to simulate multiple structures, using different models, whereas certain characteristics can be varied. Complicated structural systems can be more effectively simulated with software that is designed according to the OOP paradigm and exploits the provided abstraction, encapsulation, information hiding, inheritance, and polymorphism mechanisms. To fully utilize the advantages of OOP in structural analysis software, certain OOPs should also be followed, from the initial software analysis and design phases. Optimized solutions of recurring software design problems can be employed with the employment of Design Patterns (DPs) [9], in order to design and develop software in ways that manage its size and complexity. The presented research projects use custom-made Object-Oriented (OO) software $[10,11]$ that exploits DPs to ensure the desired maintainability and extensibility to the continually changing research needs. Modern OOP and DPs, as well as the Java programming language, are utilized to reduce the software development time, considering future revisions and extensions, especially as the size and complexity of structural analysis code increase.

\section{BILINEAR VS. BOUC-WEN MODELLING FOR LRBS}

\subsection{Modelling and simulation assumptions}

The presented results are from planar analyses of a typical five-storey seismically isolated building, with a 340 tons lumped mass at each floor level, a roof mass of 250 tons, and an additional mass of 340 tons at the seismic isolation level. The superstructure is assumed to behave as a shear beam with linear elastic behaviour, horizontal stiffness of $600 \mathrm{MN} / \mathrm{m}$ at each storey, and a corresponding $2.0 \%$ viscous damping ratio. The seismic isolation system is designed so that the fundamental eigenperiod of the base-isolated building takes two different values, 1.6 and 2.0 seconds at the design displacement, that are sufficiently longer than the fundamental eigenperiod of the corresponding fixed-supported building, which equals 0.50 seconds. The peak response of the base-isolated building is investigated under 10 selected near-fault earthquake excitations (Table 1), which are scaled so as to have a peak ground acceleration (PGA) of $0.35 \mathrm{~g}$.

Table 1: Characteristics of the selected near-fault ground excitations (unscaled).

\begin{tabular}{|c|c|c|c|c|}
\hline & Symbol earthquake event & $M_{w}$ & Station/component & PGA $(g)$ \\
\hline 4 & Izmit-Kocaeli, Turkey (1999) & 7.4 & Gebze, Comp 000 & 0.244 \\
\hline$x$ & Northridge, USA (1994) & 6.7 & Sylmar - Converter Station, Comp 052 & 0.612 \\
\hline 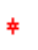 & Cape Mendocino, USA (1992) & 7.1 & Eureka - Myrtle \& West, Comp 090 & 0.178 \\
\hline$\square$ & Duzce, Turkey (1999) & 7.1 & Duzce, Comp 270 & 0.535 \\
\hline+ & Tabas, Iran (1978) & 7.4 & Tabas, TR & 0.851 \\
\hline$\diamond$ & Loma Prieta, USA (1989) & 7.0 & Saratoga - Aloha Ave, Comp 090 & 0.324 \\
\hline 古 & Loma Prieta, USA (1989) & 7.0 & Coyote Lake Dam, Comp 285 & 0.179 \\
\hline * & Coyote Lake, USA (1979) & 5.7 & Gilroy Array \#3, Comp 140 & 0.228 \\
\hline$\Delta$ & Northridge, USA (1994) & 5.7 & Beverly Hills-14145, Comp 279 & 0.516 \\
\hline$\circ$ & Kalamata, Greece (1986) & 5.9 & Kalamata, N-S & 0.248 \\
\hline
\end{tabular}




\subsection{Selected parametric analysis results}

The maximum relative displacements at the isolation level and the peak absolute top-floor accelerations are considered and a percentage mean error (PME) measure is defined in order to quantify the discrepancies of the dynamic peak response that is obtained using the bilinear inelastic model, with respect to the response obtained with the more accurate Bouc-Wen model, as:

$$
\mathrm{PME}=\% \text { mean error }=\frac{1}{n} \sum_{q=1}^{n} \frac{(B L)_{q}-(B W)_{q}}{(B W)_{q}} \cdot 100
$$

where $(B L)_{q}$ and $(B W)_{q}$ are the maximum absolute response quantities of the MDOF structure subjected to an earthquake $q$ considering a bilinear inelastic and a Bouc-Wen force-deformation behaviour of the LRBs, respectively. Positive sign of the PME indicates an overestimation of the peak response that is obtained using the bilinear model compared with the more accurate values obtained using the Bouc-Wen model, whereas a negative sign of the PME indicates an underestimation of the peak response while using the bilinear inelastic model. Because the discrepancies between the peak responses computed with the two nonlinear models are greatly influenced by the earthquake characteristics, the percentage mean error and the PME plus/minus one standard deviation for the 10 earthquake excitations are used to obtain the main tendency and the variability of the response error. The shaded areas on either side of the provided mean plots indicate the plus or minus one standard deviation of the PME.

\subsubsection{Influence of the degree of nonlinearity}

The nonlinearity degree of the LRBs can be expressed through the stiffness hardening ratio, $\alpha$, which is defined as the ratio of the post-yield to the elastic stiffness, $K_{\text {postyield }} / K_{\text {elastic }}$. Figure 3 provides the percentage mean errors plus/minus one standard deviation of the maximum relative displacements at the seismic isolation level and the peak absolute top-floor accelerations of the five-storey base-isolated building under the 10 selected earthquake ground motions, scaled to a PGA of $0.35 \mathrm{~g}$, whereas the $F_{y i} / W_{\text {tot }}$ ratio of the LRBs for all performed simulations is set to 0.05 and the stiffness hardening ratio is varied between the values of 0.067 and 0.2 .
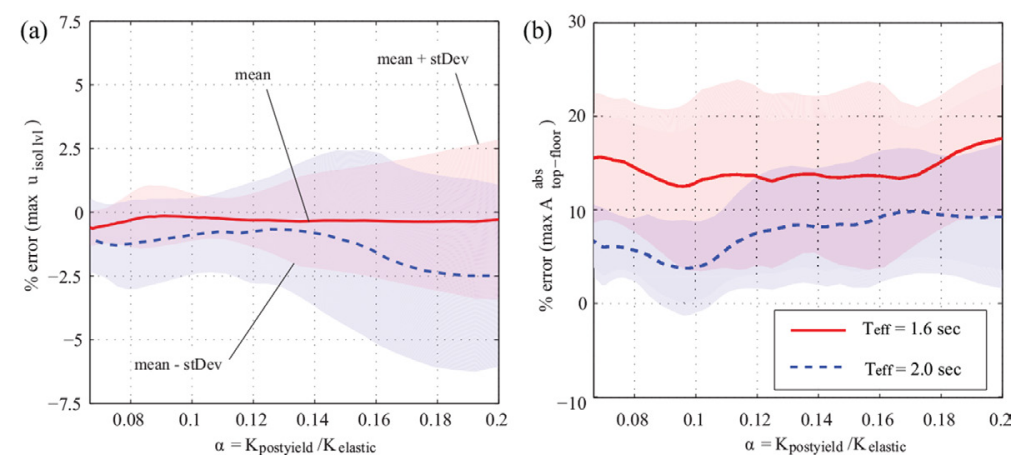

Figure 3: Percentage averaged errors \pm one standard deviation of the peak: (a) relative displacement and (b) top-floor absolute acceleration. 

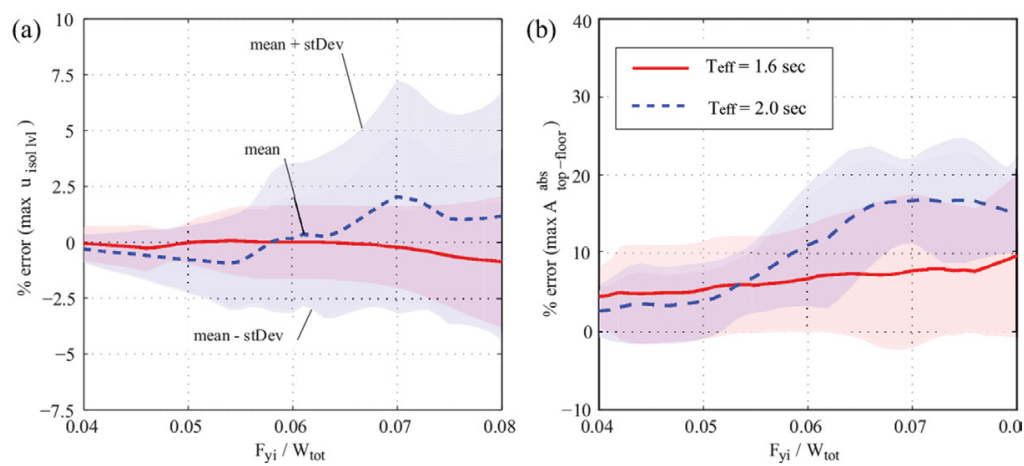

Figure 4: Percentage averaged errors \pm one standard deviation of the peak response values in terms of the $F_{y i} / W_{t o t}$ ratio.

The PME of the relative displacements at the base isolation level using the bilinear model, as shown in Fig. 3a, is underestimated up to $2.5 \%$ for the examined effective fundamental eigenperiods. The stiffness hardening ratio does not considerably influence the average error of the base drifts, which are influenced mostly by the characteristics of the earthquake excitations. The computed simulation results indicate that as the stiffness hardening ratio increases the standard deviation of the PMEs has a tendency to increase, reaching values up to approximately $3.0 \%$. As shown in Fig. 3b, the average error of the maximum absolute top-floor accelerations of the five-storey building is kept at positive values. Overall, the PME of the peak accelerations is between $5.0 \%$ and $17.5 \%$, with the maximum top-floor accelerations of base-isolated buildings using the bilinear model overestimated, whereas the standard deviations of the PMEs are relatively constant at approximately $8.0 \%$.

\subsubsection{Influence of the $F_{y i} / W_{t o t}$ ratio}

Next, the effect of the LRBs' characteristic yield strength, $F_{y i}$, normalized by the total weight acting on the isolators, $W_{t o t}$, on the percentage mean error of the computed maximum responses while using the simpler bilinear inelastic model, instead of the more accurate Bouc-Wen model, is examined. Figure 4 presents the PMEs plus/minus one standard deviation of the peak relative displacements at the base isolation level and the maximum absolute top-floor accelerations for the five-storey base-isolated buildings, considering both effective fundamental eigenperiods, for varying $F_{y i} / W_{t o t}$ ratio and with the stiffness hardening ratio set to 0.10 .

While varying the $F_{y i} / W_{t o t}$ ratio, no specific pattern of the averaged errors of the maximum base drift is observed in Fig. 4a. However, the standard deviation of the error tends to increase with the increase of the $F_{y i} / W_{\text {tot }}$ ratio reaching values up to about $5.0 \%$. The maximum response quantities seem to be affected by the characteristics of both the isolators and the selected earthquake ground motions. For systems with an $F_{y i} / W_{\text {tot }}$ ratio lower than 0.05 , usage of the bilinear model for the LRBs slightly underpredicts the mean peak relative base displacements. The average error of the absolute top-floor accelerations, as shown in Fig. 4b, increases with the increase of the $F_{y i} / W_{t o t}$ ratio, for both effective fundamental eigenperiods of 1.6 and $2.0 \mathrm{~s}$, whereas the standard deviation demonstrates a minor variability. Overall, PMEs of the peak response of base-isolated buildings mounted on LRBs modelled by bilinear hysteretic behaviour are significantly reduced for systems with lower normalized characteristic strength. It is apparent from the plotted results that, 
at least for near-fault ground motions, the maximum top-floor accelerations are in general, overpredicted when the bilinear inelastic model is used, instead of the more accurate Bouc-Wen model.

\section{STRUCTURAL POUNDING OF BASE-ISOLATED BUILDINGS}

Next, selected results from parametric analyses that have been conducted to investigate earthquake-induced pounding of a base-isolated building with both the surrounding moat wall and other adjacent buildings [12] are presented.

\subsection{Modelling and simulation assumptions}

A four-storey base-isolated building [12], assuming a shear beam behaviour for its superstructure (with a horizontal stiffness of $600 \mathrm{MN} / \mathrm{m}$ of each storey, lumped masses of 320 tons at each floor, except of the top floor with 250 tons) and a seismic isolation system simulated with a bilinear inelastic model $\left(K_{\text {elastic }}=200 \mathrm{MN} / \mathrm{m}, K_{\text {postyield }}=25 \mathrm{MN} / \mathrm{m}\right.$ and $\left.F_{y l} / W_{\text {tot }}=0.1\right)$ is considered in six different configurations: standing alone and surrounded by both the moat wall and adjacent fixed-supported buildings, with the same storey-stiffness and floor masses as the superstructure of the seismically isolated building, but with five different numbers (2 to 6) of stories in height. Both cases of pounding of the base-isolated building against the surrounding moat wall and against either the moat wall (at the isolation level) or the adjacent buildings (at the levels of the upper floors of their superstructures) are considered. These structures are subjected to five selected earthquake records (Table 2), which are characterized by low-frequency content.

The size of the seismic gap is selected to be $10 \%$ smaller than the maximum relative displacement at the seismic isolation level of the base-isolated building under each specific seismic excitation. The maximum induced relative displacements at the base and the top of the seismically isolated building, as well as the relative displacements of the tops of the fixed-supported buildings, are provided in Table 3.

In the current study, a modified force-based viscoelastic impact model is used, assuming an impact spring and an impact dashpot exerting, in parallel, impact forces to the colliding structures whenever their separation distances are exceeded, omitting tensile forces arisen at the end of the restitution period and allowing a small plastic deformation, which increases the available clearance [8].

\subsection{Selected simulation results}

Figures 5 and 6 present the amplification factors of the peak floor accelerations and interstorey deflections, respectively, of the four-storey base-isolated building considering

Table 2: Earthquake records that are used in the conducted simulations.

\begin{tabular}{llll}
\hline Earthquake event & $M_{w}$ & Station/Component & PGA (g) \\
\hline Kobe, Japan (1995) & 6.9 & 0 KJMA & 0.821 \\
Northridge, USA (1994) & 6.7 & 74 Sylmar - Converter Station & 0.897 \\
Northridge, USA (1994) & 6.7 & 24514 Sylmar - Olive View Med FF & 0.604 \\
Kocaeli, Turkey (1999) & 7.4 & Sakarya & 0.628 \\
San Fernando, USA (1971) & 6.6 & Pacoima Dam, S16 & 1.170 \\
\hline
\end{tabular}


Table 3: Maximum relative displacements $(\mathrm{cm})$ of the base-isolated building and the fixed-supported buildings, under the five seismic excitations that are used.

\begin{tabular}{|c|c|c|c|c|c|c|}
\hline Earthquake excitation & $\begin{array}{c}\text { (Base-Top) } \\
\bar{E} \\
\overline{\underline{\underline{E}}}\end{array}$ & $\begin{array}{l}\text { (Top) } \\
\text { = }\end{array}$ & $\begin{array}{l}\text { (Top) } \\
\overline{ }\end{array}$ & $\begin{array}{l}\text { (Top) } \\
= \\
=\end{array}$ & $\begin{array}{l}\text { (Top) } \\
\bar{E} \\
\bar{E}\end{array}$ & $\begin{array}{l}\text { (Top) } \\
\equiv \\
\equiv\end{array}$ \\
\hline Kobe & $16.74-18.85$ & 1.49 & 5.57 & 11.40 & 16.88 & 15.22 \\
\hline Northridge Conv. & $31.71-35.25$ & 1.49 & 3.41 & 6.43 & 10.50 & 17.70 \\
\hline Northridge Olive & $15.63-17.07$ & 1.18 & 3.28 & 5.60 & 9.75 & 13.54 \\
\hline Sakarya & $11.40-12.51$ & 2.12 & 4.50 & 5.23 & 6.30 & 7.51 \\
\hline San Fernando & $26.78-29.52$ & 3.47 & 5.67 & 14.61 & 13.40 & 8.66 \\
\hline
\end{tabular}
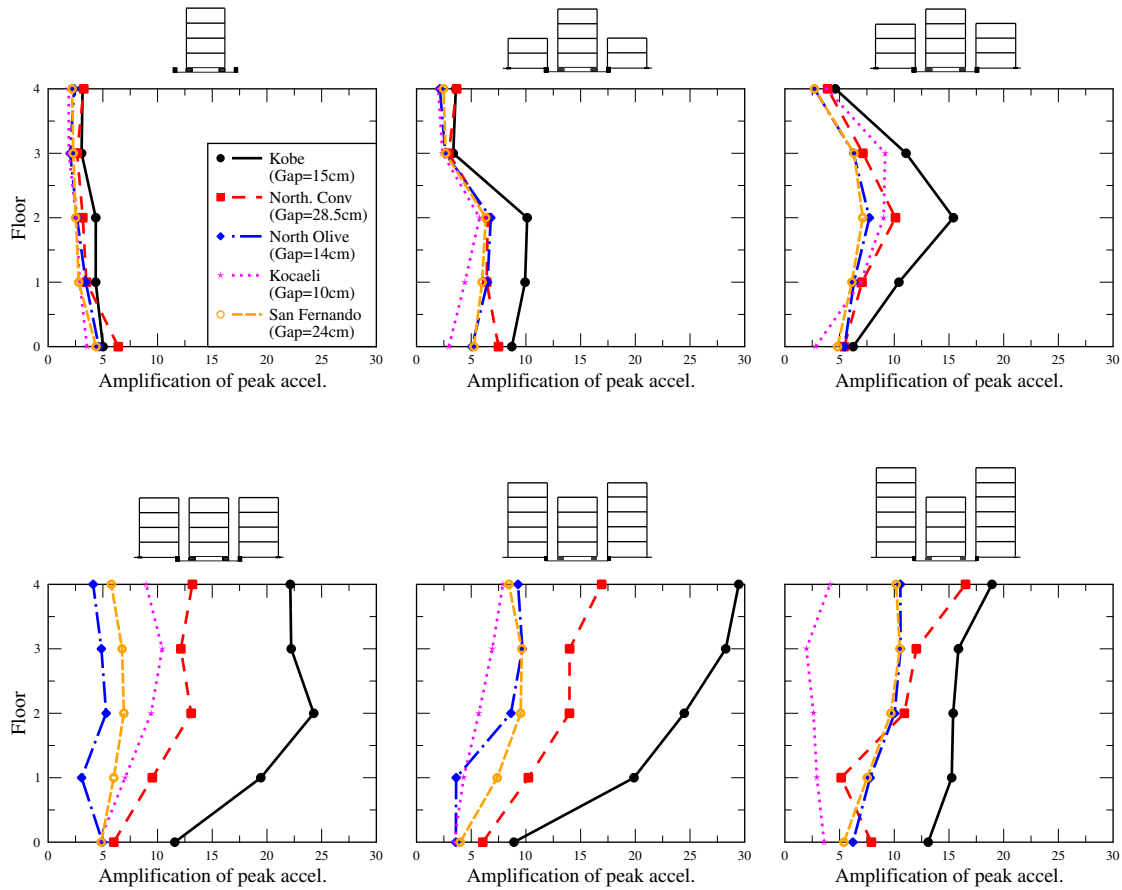

Figure 5: Amplification of the peak floor accelerations of the base-isolated building during pounding with adjacent multi-storey buildings for gap $10 \%$ smaller than the maximum base drifts, for each earthquake record.

poundings with the adjacent buildings. The amplification factor is defined as the ratio of the maximum response quantity of interest when poundings occur divided by the corresponding maximum response value without poundings. According to the simulation results, the peak total accelerations as well as the interstorey deflections and, therefore, the storey shear forces of the seismically isolated building significantly increase due to poundings that occur when the available seismic gap is slightly surpassed. In addition, it is observed that the amplification of the peak floor accelerations is, in general, greater than the ampli- 

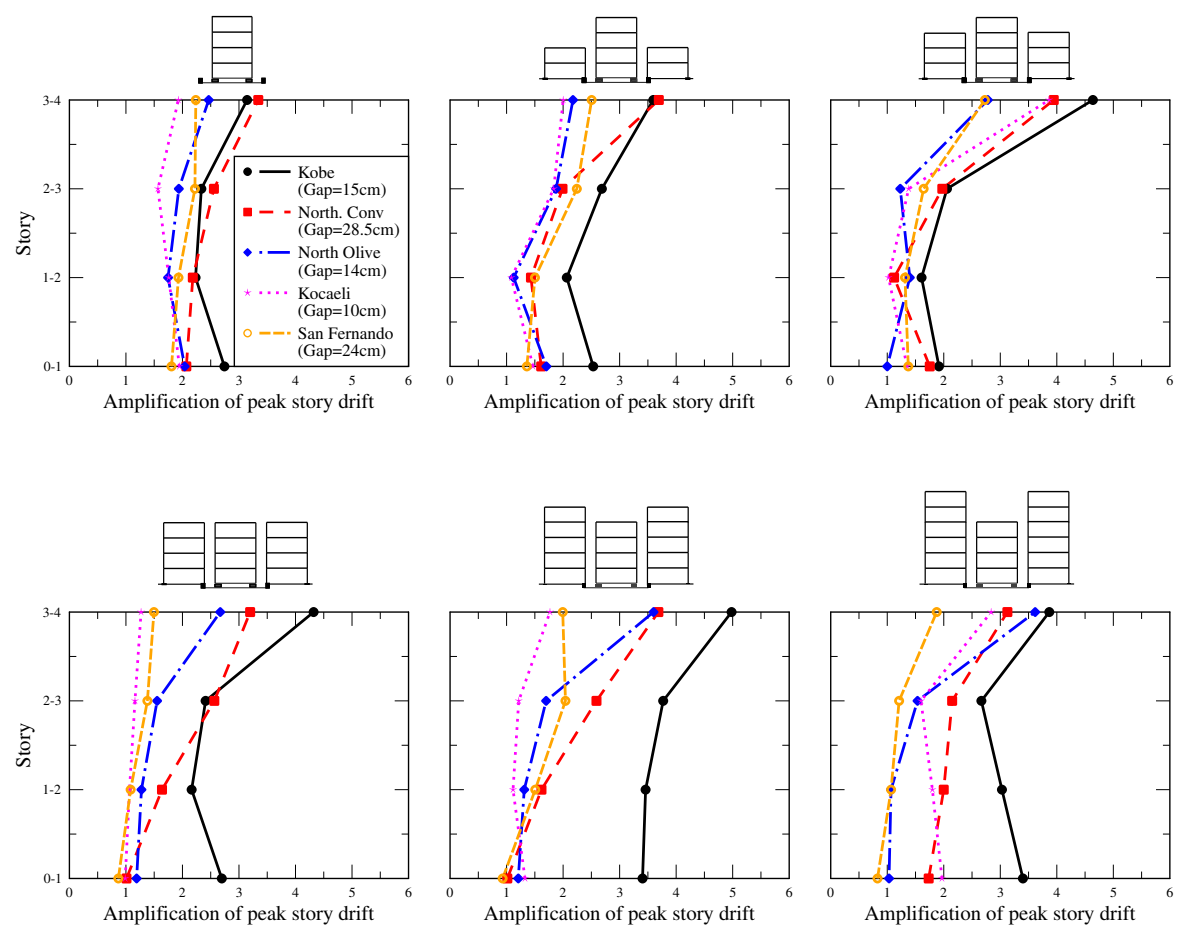

Figure 6: Amplification of the peak interstorey deflections of the base-isolated building during pounding with adjacent multi-storey buildings for gap 10\% smaller than the maximum-induced relative displacement at the seismic isolation level, for each earthquake record.

fication of the peak interstorey deflections, because the former are much more sensitive to local impacts. The maximum amplification of the acceleration response is usually located (1) at the isolation level (for the case of impact only with the moat wall), (2) at the floor that is at the same level with the roof of the adjacent structures, or (3) at the top floor of the seismically isolated building when that is shorter than the adjacent fixed-supported buildings.

The amplifications of the response of the seismically isolated building due to structural poundings depend on the earthquake characteristics in combination with the number of stories and the flexibility of the adjacent buildings. In the case of the seismically isolated building between other multi-storey fixed-supported buildings, which have different dynamic responses under each excitation, the amplification curves for each earthquake record have significant dispersions, with the worst-case scenario the one with the adjacent fixed-supported buildings having fundamental eigenfrequencies in resonance with the dominant frequencies of the earthquake excitation.

Another series of parametric analyses is performed to investigate how the width of the seismic gap may affects the response of the seismically isolated building in the six different configurations. Specifically, the width of the clearance between the base-isolated building and the adjacent conventionally fixed-supported structures is varied between 10 and $45 \mathrm{~cm}$, with a step of $0.5 \mathrm{~cm}$, simultaneously on both sides of the building. 

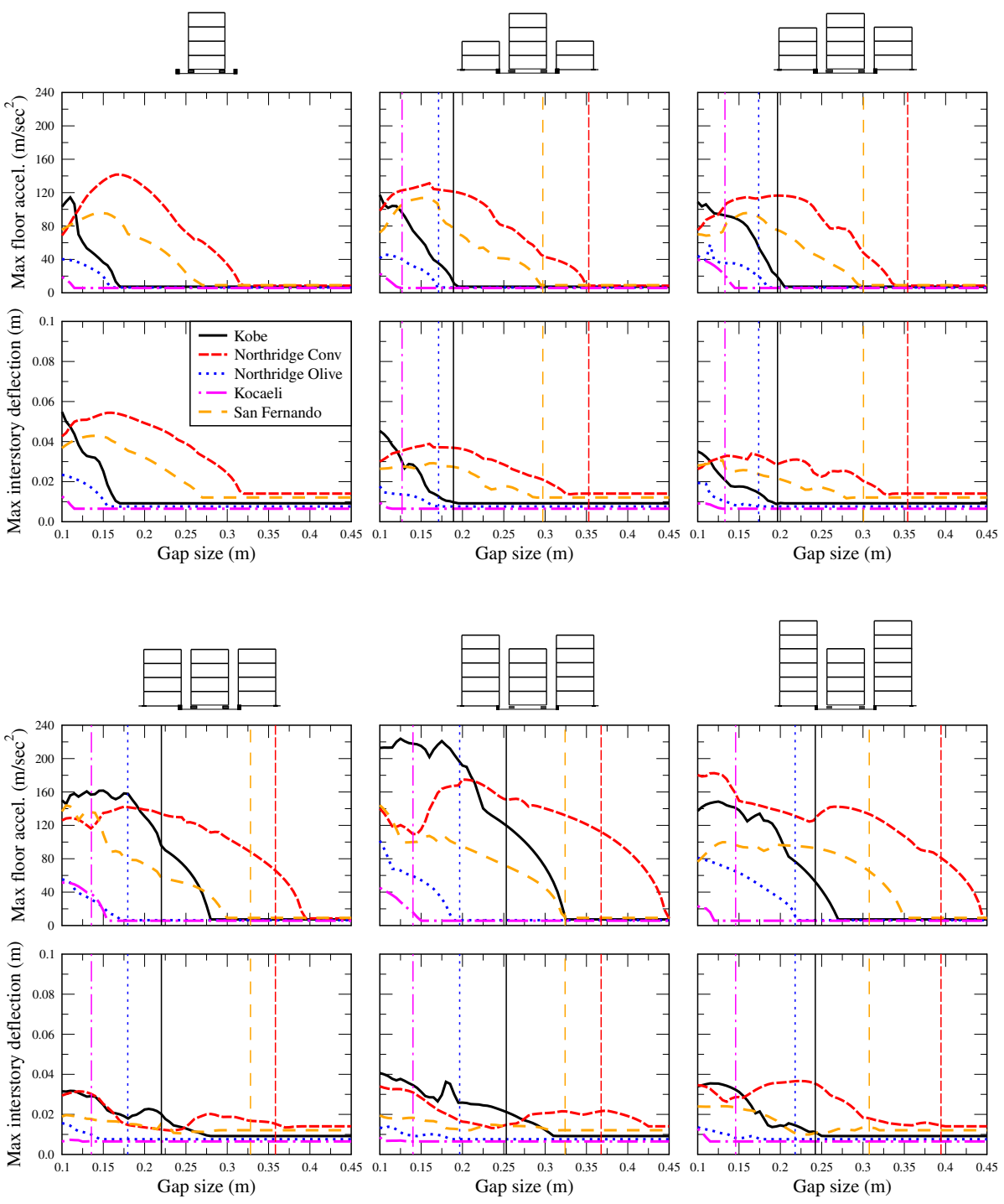

Figure 7: Peak responses of the seismically isolated building in terms of the seismic gap during pounding with adjacent multi-storey buildings.

Figure 7 presents the peak responses of the base-isolated building for a varying width of the seismic gap for the six-configurations and the five seismic excitations. The vertical lines correspond to the square root of the sum of squares (SRSS) of the peak relative displacements of the adjacent buildings for each considered case. The response, in general, decreases with the increase of the width of the clearance, also known as seismic gap, although it is not always the case, especially in cases of narrow gap sizes. In particular, very narrow seismic gaps, in combination with strong earthquake excitations, do not allow the structure to develop high-impact velocities as in cases of wider seismic gaps, leading to relatively less significant consequences from pounding. 
Table 4: The difference $\Delta d=d_{S R S S}-d_{\operatorname{Re} q}(\mathrm{~cm})$.

\begin{tabular}{lrrrrr}
\hline Earthquake excitation & 目目目 & 目目目 & 目目目 & 目目目 & 目目目目 \\
\hline Kobe & $\mathbf{- 0 . 0 9}$ & $\mathbf{- 0 . 3 4}$ & $\mathbf{- 5 . 4 7}$ & $\mathbf{- 6 . 7 0}$ & $\mathbf{- 1 . 7 7}$ \\
Northridge Conv. & 0.78 & 1.91 & $\mathbf{- 3 . 1 7}$ & $\mathbf{- 7 . 7 2}$ & $\mathbf{- 5 . 0 6}$ \\
Northridge Olive & 0.61 & $\mathbf{- 0 . 6 2}$ & 2.46 & 1.66 & 0.29 \\
Sakarya & 0.69 & $\mathbf{- 0 . 7 0}$ & $\mathbf{- 1 . 4 4}$ & 0.01 & 3.59 \\
San Fernando & 0.72 & 1.06 & 3.31 & 0.42 & $\mathbf{- 3 . 7 4}$ \\
\hline
\end{tabular}

Modern anti-seismic codes suggest the usage of the SRSS for the estimation of the required minimum seismic gap between two adjacent buildings in order to avoid structural pounding between them during strong earthquakes. In almost half of the cases that are analyzed in the current study, a seismic gap, equal to the SRSS of the design peak relative displacements of the adjacent structures, is insufficient under the specific earthquake excitations.

Specifically, Table 4 displays the difference $\Delta d=d_{S R S S}-d_{\operatorname{Re} q}$ for each one of the cases that have been considered for the configurations of the adjacent buildings and for all five earthquake excitations, where $d_{S R S S}=\sqrt{\left(\max d_{\text {iso }}\right)^{2}+\left(\max d_{\text {fixed }}\right)^{2}}$ and $d_{\operatorname{Re} q}$ is the minimum required seismic gap in order to avold structural pounding according to the performed simulations. The terms $\max d_{\text {iso }}$ and $\max d_{\text {fixed }}$ represent the maximum horizontal displacement of the seismically isolated building and its adjacent fixed-supported building, respectively, under the same earthquake excitation. Thus, the negative sign of the difference $\Delta d$ denotes that a seismic gap width equal to $d_{S R S S}$ is insufficient.

The results indicate that the presence of conventionally fixed-supported buildings in close distance to a base-isolated building may affect significantly the peak response of the latter during poundings. Generally, the amplifications of the absolute peak floor accelerations due to structural impact increase with the number of stories of the adjacent buildings. Structural pounding may occur for much wider widths of the seismic gap compared with the case of impact occurring only at the base of the seismically isolated building with the moat wall, due to the deformation of the adjacent structures. Furthermore, the base-isolated building may pound against the neighboring buildings at the upper stories, due to the deformations of the superstructures of the buildings in series, before hitting the surrounding moat wall. The characteristics of the earthquake excitation, such as the range of the predominant periods, in combination with the fundamental eigenperiods of the adjacent structures seem to play an important role to the harshness of the structural impact. In particular, the damaging effects of structural pounding are more pronounced when the fundamental eigenperiods of the adjacent fixed-supported buildings fall within the predominant periods of the earthquake excitation.

\section{CONCLUDING REMARKS}

Both research works from which selected results have been presented utilize OOP software specifically designed and developed in order to effectively perform the necessary numerical simulations and parametric analyses. In general, the bilinear model underestimates the 
relative displacements at the isolation level and overestimates the peak floor accelerations. The detrimental effects of pounding are more pronounced when the neighbouring fixed-supported structures, to the base-isolated building, are in resonance with the seismic excitation and the SRSS method for the estimation of the required separation distance between a base-isolated building and its adjacent fixed-supported buildings may not be sufficient. Based on this observation, additional practical measures for mitigating the detrimental effects of earthquake-induced pounding, such as the usage of rubber shock-absorbers $[13,14]$, might be considered.

\section{ACKNOWLEDGEMENTS}

This work is deeply influenced by research performed at MIT under the guidance, supervision, and encouragement of Prof. Jerry Connor, a pioneer in structural engineering, an inspiring mentor, and a really generous teacher.

\section{REFERENCES}

[1] Komodromos, P., Seismic Isolation for Earthquake Resistant Structures, WIT Press: Southampton, 2000.

[2] Skinner, R.I., Robinson, W.H. \& McVerry, G.H., An Introduction to Seismic Isolation, John Wiley \& Sons Ltd: West Sussex, UK, 1993.

[3] Higashino, M. \& Okamoto, S., Response Control and Seismic Isolation of Buildings, Taylor \& Francis: Oxon, UK, 2006. doi: http://dx.doi.org/10.4324/9780203018866

[4] Park, Y.J., Wen, Y.K. \& Ang, A.H.-S., Random vibration of hysteretic systems under bi-directional ground motions. Earthquake Engineering Structural Dynamics, 14, pp. 543-557, 1986. doi: http://dx.doi.org/10.1002/eqe.4290140405

[5] Polycarpou, P.C. \& Komodromos, P., On poundings of a seismically isolated building with adjacent structures during strong earthquakes. Earthquake Engineering and Structural Dynamics, 39(8), pp. 933-940, 2010. doi: http://dx.doi.org/10.1002/eqe.975

[6] Masroor, A. \& Mosqueda, G., Experimental simulation of base-isolated buildings pounding against moat wall and effects on superstructure response. Earthquake Engineering and Structural Dynamics, 41(14), pp. 2093-2109, 2012. doi: http://dx.doi. org/10.1002/eqe. 2177

[7] Matsagar, V.A. \& Jangid, R.S., Seismic response of base-isolated structures during impact with adjacent structures. Engineering Structures, 25, pp. 1311-1323, 2003. doi: http://dx.doi.org/10.1016/s0141-0296(03)00081-6

[8] Komodromos, P., Polycarpou, P.C., Papaloizou, L. \& Phocas, M.C., Response of seismically isolated buildings considering poundings. Earthquake Engineering and Structural Dynamics, 36, pp. 1605-1622, 2007. doi: http://dx.doi.org/10.1002/eqe.692

[9] Gamma, E., Helm, R., Johnson, R. \& Vlissides, J., Design Patterns: Elements of Reusable Object-Oriented Software, Addison Wesley, 1995.

[10] Mavronicola, E. \& Komodromos P., Assessing the suitability of equivalent linear elastic analysis of seismically isolated multi-storey buildings, Computers and Structures, 89(21-22), pp. 1920-1931, 2011. doi: http://dx.doi.org/10.1016/j.compstruc.2011.05.010

[11] Komodromos, P. \& Polycarpou, P., Utilization of object-oriented programming, design patterns and java for simulating earthquake-induced poundings of base isolated buildings. International Journal of Computational Methods and Experimental Measurements, 1(1), pp. 37-54, 2013. doi: http://dx.doi.org/10.2495/cmem-v1-n1-37-54 
[12] Polycarpou, P. \& Komodromos, P., Earthquake-induced poundings of a seismically isolated building with adjacent structures. Engineering Structures, 32, pp. 1937-1951, 2010. doi: http://dx.doi.org/10.1016/j.engstruct.2010.03.011

[13] Polycarpou, P. \& Komodromos, P., Numerical investigation of potential mitigation measures for poundings of seismically isolated buildings. Earthquakes and Structures, 2(1), pp. 1-24, 2011.

[14] Polycarpou, P., Komodromos, P. \& Polycarpou, A., A nonlinear impact model for simulating the use of rubber shock absorbers for mitigating the effects of structural pounding during earthquakes. Earthquake Engineering and Structural Dynamics, 42, pp. 81-100, 2013. doi: 10.1002/eqe. 2194 